\title{
Diagnosis and Non-Surgical Management of Urinary Incontinence - A Literature Review with Recommendations for Practice
}

\author{
Eabhann O'Connor' \\ Aisling Nic an Riogh (D) $^{2}$ \\ Markos Karavitakis ${ }^{3}$ \\ Serenella Monagas ${ }^{4}$ \\ Arjun Nambiar ${ }^{5}$ \\ 'Department of Urology, Beaumont \\ University Hospital, Dublin, Ireland; \\ ${ }^{2}$ Department of Urology, Cork University \\ Hospital, Cork, Ireland; ${ }^{3}$ Department of \\ Urology, University General Hospital of \\ Heraklion, University of Crete, Irakleio, \\ Greece; ${ }^{4}$ Department of Urology, San \\ Agustín University Hospital, Avilés, Spain; \\ ${ }^{5}$ Department of Urology, Freeman \\ Hospital, Newcastle-upon-Tyne, UK
}

Correspondence: Eabhann O'Connor Email eabhannoconnor@beaumont.ie

\begin{abstract}
Urinary incontinence (UI) is a bothersome symptom with population studies suggesting a prevalence of $13.1 \%$ in women and $5.4 \%$ in men. While a significant cohort of patients with this complaint may ultimately require surgical management to achieve complete continence, a number of non-surgical measures exist to improve symptoms and quality of life. A range of guidelines exist on this topic, including those published by the European Association of Urology (EAU), the International Continence Society (ICS), the American Urological Association (AUA) and the UK's National Institute for Health and Care Excellence (NICE). The aim of our study is to provide an overview of the initial assessment of patients with UI including history taking, examination and basic investigations. Our review outlines non-surgical management strategies for UI, including conservative measures, behavioral and physical therapies and drug treatment. We shall also examine the above guidelines and present a narrative overview of the literature surrounding the diagnosis and non-surgical management of urinary incontinence.
\end{abstract}

Keywords: urinary incontinence, conservative, non-surgical, behavioral, physical, drug treatment

\section{Introduction}

Urinary incontinence (UI) is the complaint of any involuntary leakage of urine. It is a common condition, which may have a significant negative impact on an individual's quality of life. Population studies suggest a prevalence of $13.1 \%$ in women and $5.4 \%$ in men. ${ }^{1}$ UI may affect any individual of any age but most commonly affects men and women sixty years or older. ${ }^{1}$ While there are an extensive range of potential etiologies in all age groups, our review shall specifically focus on nonneurogenic urinary incontinence affecting adult patients.

A number of guidelines exist, including those published by the European Association of Urology (EAU), ${ }^{2}$ the International Continence Society (ICS), ${ }^{3}$ the American Urological Association (AUA)/Society of Urodynamics, Female Pelvic Medicine \& Urogenital Reconstruction (SUFU) ${ }^{4-6}$ and the UK's National Institute for Health and Care Excellence (NICE) ${ }^{7}$ on the diagnosis and non-surgical management of non-neurogenic incontinence. Our goal is to provide a broad overview of the key components of the assessment and initial management of these patients.

UI may be classified in a number of ways based on the predominant symptom constellation and underlying pathophysiology. UI may be classified as stress UI, 
urgency UI or mixed UI, which contains symptoms of both stress and urgency UI. Other categories of UI include overflow incontinence, nocturnal enuresis, postmicturition dribble, continuous incontinence (as is often experienced with a vesicovaginal fistula), or insensible incontinence, where an individual may be unaware of how it occurred.

\section{Methods}

A search of the Medline/PubMed electronic database was performed for dates up to February 2021. The search terms used included "urinary incontinence" and "diagnosis" or "non-surgical management" or "conservative management" or "drug treatment" or "behavioral therapy" or "physical therapy". Further studies were chosen on the basis of manual searches of reference lists and review papers and from meetings of the European Association of Urology (EAU), the American Urological Association (AUA), the Society of Urodynamics, Female Pelvic Medicine \& Urogenital Reconstruction (SUFU) and the International Continence Society (ICS). Various guideline organizations were also searched for existing practice guidelines and systematic reviews on diagnosis and nonsurgical management of urinary incontinence.

\section{Results}

\section{History}

History taking remains an integral component in elucidating possible underlying etiologies for and impact on the quality of life of an individual's UI. Details of a patient's UI should include duration and onset of UI and severity of symptoms (including impact on quality of life). It is critical to enquire about predisposing and aggravating factors, which may point towards etiology and guide initial conservative management by modifying reversible factors.

Predisposing factors include:

1. Female gender

2. Genetic predisposition

3. Race (The EPI study [Establishing the Prevalence of Incontinence] found that the prevalence of UI was significantly higher in white women than black women $[33.1 \%$ vs $14.6 \%])^{8}$

4. Anatomical disorders (vesicovaginal fistula, urethral diverticulum, urethral fistula, bladder exstrophy or epispadias)

5. Diabetes mellitus

\section{Pregnancy}

7. Childbirth (increasing parity, assisted vaginal delivery including ventouse or forceps extraction)

8. Connective tissue disorders including EhlersDanlos syndrome

9. Pelvic, perineal or prostate surgery

10. Pelvic radiotherapy

Aggravating factors include:

1. Ageing

2. Cognitive deficits and poor mobility

3. Poor nutritional status

4. Increased fluid or excessive caffeine intake ${ }^{9}$

5. Obesity $^{10}$

6. Smoking (may cause chronic cough and subsequent raised intra-abdominal pressure $)^{11}$

7. Urinary tract infection (UTI)

8. Estrogen deficiency

9. Medications (including antipsychotics, diuretics and alpha-blockers, especially in women $)^{12}$

It is important to enquire about "red flag" symptoms, which require further investigations, such as pain, hematuria, recurrent UTI or significant voiding or obstructive symptoms as these may indicate issues such as underlying malignancy, as well as to ask about bowel function and symptoms of sexual dysfunction and pelvic organ prolapse in women. In patients with cognitive deficits, it is imperative to obtain a collateral history from caregivers to identify potential risk factors for UI as outlined above.

\section{Questionnaires}

It can be helpful to utilize a validated patient-completed questionnaire to assess initial symptoms and subsequently to monitor patient-reported outcomes following intervention. The most commonly used questionnaires in clinical practice are the ICIQ-UI short form for men and women to assess symptom score and quality of life. The ICIQFLUTS and ICIQ-MLUTS assess symptoms in female and male patients, respectively. Advantages of the ICIQ questionnaires are that they are validated across a range of populations and available in a number of different languages. ${ }^{13}$ It should be remembered, however, that many health questionnaires and patient-reported outcome measures were developed and tested in patients with lower urinary tract symptoms, not specifically for UI, and should therefore be used with some caution in these populations. ${ }^{7}$ 


\section{Physical Examination}

A chaperoned physical examination is a crucial component of the assessment of the patient with UI. Patients should be weighed and their body mass index recorded. In the supine position, an abdominal examination should be performed, particularly assessing for a palpable bladder or any abdominal masses.

In women, a pelvic examination should be performed initially in the supine position. It is important to inspect the introitus to glean whether it is well estrogenised or whether there is evidence of atrophic vaginitis. Ask the patient to cough or perform a Valsalva maneuver to elicit potential stress urinary incontinence. Pelvic tone may also be assessed and graded using the Oxford grading system.

The patient should then be asked to turn to the left lateral position, and the chaperone can assist in lifting the upper leg. A warm, lubricated Sim's speculum should be introduced into the vagina to assess pelvic organ prolapse. If a urinary tract fistula is suspected, it may be possible to palpate a defect or see urine pooling in the vagina.

Neurological examination in both sexes should include assessment of gait, anal tone, perineal sensation and lower limb function. Men should have a digital rectal examination performed to assess the prostate.

"Red flag" signs in either gender that require further investigation include urethral, bladder, or pelvic masses, hematuria, new neurological deficit and suspected fistula.

\section{Basic Investigations}

UTI may exacerbate or cause UI. As such, a urinalysis should be performed on all patients presenting with UI and patients reassessed for UI symptoms following treatment of infection. Patients with persistent non-visible hematuria should also be assessed with cystoscopy and upper tract imaging. However, treating asymptomatic bacteriuria has not been shown to improve symptoms of UI in older nursing home residents. ${ }^{14}$

A bladder or voiding diary typically records the type and volume of fluid intake, incontinence episodes and number of pads used along with a recorded chart of urinary frequency and voided urine volume (ie functional bladder capacity). EAU guidelines recommend the use of a voiding diary of at least 3 days duration to reliably measure 24 hour and nighttime urine volumes, day- and night-time frequency, urgency, UI episodes and mean voided volume. ${ }^{2}$

Post void residual volume (PVR) assessment can be considered in selected cases if there is concern about overflow incontinence in men with bladder outflow obstruction or voiding dysfunction. EAU guidelines suggest there is no evidence to support the assessment of PVR in all patients with UI. ${ }^{2}$

Additional investigations that may be considered include perineal pad testing to quantify urine loss or urodynamic studies. Urodynamics may be considered for patients who have persistent UI or bothersome symptoms despite the non-surgical measures outlined below. They should also be performed if a neurological cause for the UI is suspected. The ICS standard urodynamic protocol includes clinical history, including symptom and bother score(s), examination, 3-day voiding chart/diary, representative uroflowmetry with post-void residual, and cystometry with pressure-flow study. ${ }^{15}$ EAU guidelines suggest that urodynamic studies should be performed if the findings may change the choice of invasive treatment, and is not recommended in the evaluation of uncomplicated isolated urgency or stress incontinence. ${ }^{2}$

\section{Non-Surgical Management of Urinary Incontinence Conservative Management}

Conservative management should be the starting point for any patient with UI. Conservative therapies are recommended as they can be effective and well tolerated and are usually associated with the least risk of harm. A stepwise approach to treatment of incontinence is typically recommended, beginning with addressing underlying medical issues and lifestyle modifications.

In patients with mixed incontinence, conservative management should be directed towards the most bothersome component of the patient's symptoms.

\section{Treatment of Co-Morbidities}

Many elderly patients will suffer from multiple medical conditions that can be associated with lower urinary tract symptoms, including UI. By addressing and optimizing these underlying diseases, it is possible that urinary tract symptoms may improve. In patients with multiple comorbidities, an individualized approach should be taken as it can be difficult to identify which condition is responsible for their symptoms. Some diseases that can impact on lower urinary symptoms are listed in the section above.

\section{Constipation}

There is a strong association between constipation and UI. ${ }^{16,17}$ A large observational study comparing women with UI and pelvic organ prolapse to controls found that 
constipation was associated with both prolapse and UI. ${ }^{18}$ In elderly patients, multimodal interventions, such as assisted toileting and managed fluid intake have been associated with a reduction in the occurrence of both UI and constipation. ${ }^{19}$ Despite this clear association, however, there is no consistent evidence that treatment of constipation alone improves UI.

\section{Containment}

When considering conservative management options, containment devices are an option, especially in patients who have failed or refused active treatment or who may not be suitable for the same. A wide variety of different containment devices are available including absorbent pads, urinary catheters, external collection devices, intravaginal devices for women and penile clamps for men. A useful resource for patients and health care professionals can be found at www.continenceproductadvisor.org.

The type of containment device used can vary depending on patient preference and their degree of incontinence. A number of randomized controlled trials (RCTs) and systematic reviews (SRs) have been carried out to assess the various different containment devices on offer and are discussed below.

A SR by Brazzelli and colleagues compared different types of pads and found that pads with superabsorbent filling were superior to standard pads. ${ }^{20}$ A two-week crossover RCT in men with UI showed that quality of life was better when using a condom sheath catheter compared to pads. ${ }^{21}$

McMurdo and associates compared pads to indwelling urethral catheters in elderly women and found that there was no difference in skin integrity score or dependency level at six months. ${ }^{22}$ Saint et al carried out a randomized control trial in hospitalized men comparing condom and indwelling catheters and highlighted that there were no differences in rates of bacteriuria or symptomatic urinary tract infection. However, patients did find the condom catheter more comfortable and less painful. ${ }^{23}$ A Cochrane review identified and summarized three RCTs comparing long-term indwelling catheters and showed no evidence that any one catheter type or material was superior to another. ${ }^{24}$ A SR of non-randomized studies identified no difference in urinary tract infection outcomes between patients using suprapubic or urethral catheters, and as might be expected, patients with suprapubic catheters were less likely to suffer from urethral complications. ${ }^{25}$

The role of antibiotic prophylaxis in adults with catheters (indwelling or intermittent) has been investigated and a Cochrane review summarizing some of these trials found that prophylaxis reduced the incidence of symptomatic UTI. $^{26}$ However, a further multicenter RCT highlighted the risk of the development of antibiotic resistance. ${ }^{27}$

Penile clamps can be effective in men with UI. A RCT found hinge type clamps to be more effective than circular clamps and they were also preferred by the participants. ${ }^{28}$ A Cochrane review summarized seven trials comparing mechanical devices in women. This reported limited evidence that UI was reduced by intravaginal devices and that there was no difference in control of UI between intravaginal and intra-urethral devices. ${ }^{29}$

\section{Lifestyle Factors}

Various lifestyle factors are associated with incontinence and modification of these factors may help improve symptoms. These include caffeine intake, ${ }^{9}$ obesity, ${ }^{10}$ smoking, ${ }^{11}$ diet, and physical activity.

\section{Caffeine Intake}

Excessive consumption of caffeinated drinks, such as tea, coffee and cola, has anecdotally been associated with worse lower urinary tract symptoms. Despite this, a number of studies investigating this topic have shown that caffeine reduction does not improve incontinence. However, a recent review of 14 interventional and 12 observational studies has shown that a reduction in caffeine can reduce symptoms of frequency and urgency. ${ }^{30}$

\section{Fluid Intake}

Modification of fluid intake is commonly recommended to people with UI to help relieve their symptoms, but there is conflicting evidence to support this. A number of RCTs investigating this topic show inconsistent results. ${ }^{31,32}$ An RCT by Hashim and colleagues showed that a reduction in fluid intake by $25 \%$ improved symptoms in patients with OAB but had minimal impact on UI. ${ }^{33}$

In general, advice should be based on 24-hour intake and output measurements with patients counselled to drink sufficient amounts to avoid thirst. Patients should be advised of the possibility of worsening constipation as a result of fluid restriction. Further investigation should be carried out in patients with low or high 24-hour urine output. ${ }^{2}$

\section{Weight Loss}

A number of epidemiological studies have shown that being overweight or obese is a significant modifiable risk factor for urinary incontinence. ${ }^{10,34,35}$ The prevalence of 
both stress and urgency urinary incontinence increases proportionally with a rising body mass index. ${ }^{36}$ A number of studies highlight that weight loss improves UI. $^{10,34,35}$ Surgical weight loss is associated with a significant improvement in UI - at least two prospective studies have revealed that bariatric surgery was associated with a substantially reduced rate of UI at 11 months and 3 years. ${ }^{36,37}$ Weight loss should be recommended as a firstline therapy for any overweight or obese patient with UI, particularly those with stress UI.

\section{Physical Exercise}

Lower levels of UI have been seen in women who undertake moderate exercises, such as walking or swimming; however, it remains unclear whether regular exercise can prevent the development of UI. ${ }^{38,39}$ Strenuous physical exercise such as running has been shown to increase the risk of stress UI during physical activity ${ }^{40,41}$ and indeed, the presence of UI may prevent some women from exercising. ${ }^{42}$ Three RCTs in the elderly, however, have shown that exercise, when used as a component in a multifactorial regime including pelvic floor exercises and weight loss can help improve UI. ${ }^{19,43,44}$

\section{Smoking}

Smoking is often proposed as a risk factor for UI as it can increase coughing episodes. However, there is very weak evidence to suggest that smoking cessation improves urinary incontinence. ${ }^{45}$ Despite this, smoking cessation is a general public health measure and should be recommended to patients. ${ }^{40,46}$

\section{Behavioral and Physical Therapies}

The International Continence Society (ICS) defines behavioral therapy as a type of psychotherapy that attempts to modify observable maladjusted patterns of behavior by substituting a new response or set of responses to a given stimulus. ${ }^{47}$ This method of treatment requires a self-motivated patient who is open to implementing retraining techniques in conjunction with an allied health professional. These behavioral and physical modifications have a role in almost all cases of UI and can be used alongside and in conjunction with other treatments. ${ }^{48}$

First-line treatment approaches include bladder training (BT), prompted voiding (PV), and pelvic floor muscle training (PFMT). Second- or third-line therapies such as electrical and magnetic stimulation (ES and EM, respectively), percutaneous tibial nerve stimulation (PTNS) and acupuncture may also be considered.

\section{Bladder Training (BT)}

This method seeks to regain continence by encouraging patients to progressively extend the time between voiding. BT may help individuals who are physically and mentally engaged, but it may take months to achieve symptom improvements. A Cochrane review including BT did not find enough rigorous evidence to prove its benefit but suggested that BT may be helpful in improving UI. ${ }^{49}$ NICE guidelines advise maintaining treatment for a minimum of 6 weeks and using the therapy in combination with drugs if frequency is a troublesome symptom. ${ }^{7}$

\section{Prompted Voiding (PV)}

Often part of a toileting program, this term implies that carers, rather than the patient, initiate the decision to void at scheduled intervals. ${ }^{50}$ It can improve urinary continence in older adults and individuals with and without physical and cognitive impairments but requires extensive and continuous staff management techniques. The most responsive individuals are those who can maintain high levels of urinary continence between two and four hourly prompted voids. ${ }^{51}$ EAU guidelines recommend offering PV to cognitively impaired adults with UI. ${ }^{50}$

\section{Pelvic Floor Muscle Training (PFMT)}

This treatment classically involves sequential contraction and relaxation of the pelvic floor musculature with the goal of strengthening these supports and thus improving UI. NICE guidelines advise that PFMT programs should comprise at least 8 contractions performed 3 times per day. ${ }^{7}$

PFMT can cure or improve SUI and all other types of UI in women. ${ }^{52}$ One RCT found that a high-intensity program of PFMT is superior at improving SUI in elderly women compared to BT alone. ${ }^{53}$ There is some evidence that improving pelvic floor function may inhibit bladder contractions in patients with OAB. ${ }^{54}$ The effect in mixed UI is lower than in women with pure SUI, but it may be augmented by combining the techniques with biofeedback. ${ }^{2}$

EAU guidelines point out that there are greater benefits seen with the addition of biofeedback and supervised highintensity regimes. However, benefits are not maintained at fifteen-year follow-up. ${ }^{50}$ NICE guidelines recommend offering a trial of supervised PFMT for at least 3 months as first-line treatment for women with SUI and continuing with an exercise program if it is beneficial. ${ }^{7}$ 
Regarding UI in men undergoing radical prostatectomy, a meta-analysis within a Cochrane review suggested that PFMT may speed recovery mainly between the third and sixth postoperative months but is unlikely to do so beyond 12 months after surgery. ${ }^{55} \mathrm{~A}$ meta-analysis has suggested that there is no benefit derived from additional preoperative PFMT. ${ }^{56}$

To summarize, EAU guidelines strongly recommend offering supervised, intensive PFMT, lasting at least 3 months, as a first-line therapy for all women with SUI or MUI (including the elderly and post-natal) as well as instruction on PFMT for men undergoing radical prostatectomy to speed recovery from UI. ${ }^{50}$

\section{Electric Stimulation}

ES with non-implanted devices using surface electrodes (skin, vaginal, anal) aims to inhibit contractions of the detrusor muscle, potentially reducing urinary frequency and urgency. The details and methods of delivery of ES vary considerably.

A 2016 Cochrane Review indicated that ES was better than PFMT, drug treatment and placebo or sham treatment at improving $\mathrm{OAB}$ symptoms of urinary frequency and urgency, but it was unclear if ES was more effective than placebo/sham for UI. The trials included were deemed to be of low quality. ${ }^{7}$

EAU and NICE guidelines do not recommend routinely offering ES alone for the treatment of SUI but advise that it can be considered for women who have difficulty contracting pelvic floor muscles to aid motivation and adherence to therapy. ${ }^{7,50}$

\section{Electrical Stimulation of the Posterior Tibial Nerve (PTNS)}

PTNS delivers electrical stimuli to the sacral micturition center via the S2-S4 sacral nerve plexus. The technique requires the insertion of a fine needle, just above the medial aspect of the ankle. Treatment cycles typically consist of twelve weekly treatments of 30 minutes. Available evidence from two SRs shows that PTNS in isolation may improve the urgency of UI compared with sham and other treatments. ${ }^{58,59}$

\section{Acupuncture}

This traditional Chinese technique is purported to improve UI by reinforcing qi (the vital substance constituting the human body) and promoting recovery of bladder function. The most commonly used acupoints are located above the first, second and third sacral foramina, which lie over the first, second and third sacral nerve roots, respectively, and correspond to the segmental innervation of the parasympathetic nerve supply to the bladder. ${ }^{60}$

A Cochrane review demonstrated that acupuncture for SUI in adults might be beneficial, but sufficient evidence to determine whether acupuncture was more effective than drug treatment was lacking. ${ }^{61}$ A recent study showed that electroacupuncture (EA) was effective in reducing SUI compared with sham electroacupuncture, and the effect persisted 24 weeks after treatment. ${ }^{62}$

In a systematic review with a meta-analysis of 10 RCTs including 794 patients, the authors reported that acupuncture may be effective in reducing OAB symptoms compared to sham treatment. ${ }^{63}$ The studies were of low quality and compared EA to sham acupuncture, or EA plus tolterodine vs tolterodine alone. Nevertheless, acupuncture is comparatively well tolerated with few adverse reactions and is safe. In the future, studies with high methodological quality and larger sample sizes are required.

\section{Drug Treatment Estrogens}

Estrogen receptors are widely distributed throughout the lower urinary tract, being present in the bladder, urethra, vagina, and pelvic floor musculature. ${ }^{64}$ Estrogens influence female urinary continence mechanisms by increasing the density of the periurethral tissues, which account for one-third of urethral pressure. ${ }^{65}$

A Cochrane review published in 2012 found that significantly more women who received local (vaginal) estrogen for UI reported that their symptoms improved compared to placebo. The same review reported that trials investigating systemic estrogen administration found that women reported worsening of their urinary symptoms. ${ }^{66}$

\section{Antimuscarinics}

Bladder function and detrusor contractility are primarily regulated by the acetylcholine signaling pathway via muscarinic receptors. ${ }^{67}$ Among the 5 known subtypes of muscarinic receptors, only M2 and M3 subtypes are found in the bladder. Anticholinergic drugs competitively inhibit binding of acetylcholine to the muscarinic receptor and increase bladder storage capacity. ${ }^{68}$

Currently available antimuscarinics include oxybutynin, solifenacin, tolterodine, darifenacin, trospium chloride and fesoterodine. There is a lack of direct comparative 
trials that could assist in selecting one antimuscarinic over another. Studies comparing short-acting oral oxybutynin with short-acting oral tolterodine demonstrated that the former is slightly more effective in controlling incontinence, but the latter has fewer anticholinergic side effects and is better tolerated. ${ }^{69}$ EAU guidelines suggest that dose escalation of antimuscarinic drugs may be adequate in selected patients to cure or improve UI but with a higher risk of side effects. They also suggest that immediaterelease formulations tend to be associated with more side effects compared with extended-release formulations and that the latter should be chosen where possible. ${ }^{2}$

A Cochrane review demonstrated that anticholinergics, as a class, are superior to placebo for treating urgency UI but was unable to demonstrate that any one agent was superior to another. ${ }^{70}$ Similarly, Ouslander et al concluded that all of the anticholinergic drugs have similar efficacy. ${ }^{71}$

Since muscarinic receptors have a broad distribution throughout the body, administration of anticholinergic drugs can result in undesirable systemic side effects. ${ }^{68}$ These can be immediate (confusion, delirium, headache, blurred vision, dizziness and hallucinations) or delayed (memory loss). ${ }^{72}$ Different types of anticholinergics can have different side effects based on pharmacokinetic properties. For example, smaller molecules, neutral in charge and lipophilic, can easily traverse the blood-brain barrier leading to central nervous system side effects.

Concerns have been raised in more recent years about the reversibility of the cognitive effects of long-term anticholinergic use. Gray et al assessed 3434 patients aged 65 and older with no dementia at study entry who were treated with various anticholinergic medications including bladder antimuscarinics, first-generation antihistamines and tricyclic antidepressants. They demonstrated that higher cumulative anticholinergic medication use was associated with an increased risk of dementia. ${ }^{73}$ It is imperative to warn younger patients in particular of this risk when prescribing bladder antimuscarinics.

A Cochrane Review of 5 of the 6 available anticholinergic drugs demonstrated that anticholinergics lead to statistically significant improvements in overactive bladder symptoms with fewer leakage episodes and voids compared to placebo. ${ }^{70}$

Discontinuation rates for anticholinergic drugs are high. D' Souza et al demonstrated that among patients treated with oxybutynin and tolterodine ER and IR, 1 year persistence rates were only $13.2 \%$, with a median time to discontinuation of 31 days. $^{74}$ A large US survey of
$>5000$ patients demonstrated that the main reasons for drug withdrawal are typically tolerability of their symptoms or unmet treatment expectations, switching to a new antimuscarinic agent or adverse effects. ${ }^{75}$

Patients with past depressive disorder, urinary infection and polypharmacy have increased odds of early discontinuation. $^{76}$

Absolute contraindications for anticholinergic use include urinary retention, gastric retention, uncontrolled narrow angle glaucoma, and known hypersensitivity to the individual drugs or any of their ingredients.

\section{Mirabegron}

The beta-adrenoceptors (AR) are classified into beta(1), beta(2), and beta(3) subtypes. The predominant adrenoceptors in bladder tissue are $\beta-3$ adrenergic receptors ( $\beta-3$ AR). ${ }^{77}$ Beta3-AR mediates relaxation of human detrusor muscle and increases bladder capacity without influencing bladder contraction. Mirabegron is currently the only available $\beta 3$ agonist, which acts on beta $_{3}$-adrenergic receptors to relax the detrusor.

Mirabegron was originally developed as a treatment for diabetes and in 2012 was approved by the FDA as a new class of drug used to treat overactive bladder symptoms. ${ }^{78}$

Mirabegron leads to one to two less incontinence episodes per day, similar to sustained-release tolterodine. ${ }^{79}$ A systematic review with nearly 6000 patients demonstrated that mirabegron was effective in treating overactive bladder, with a greater decrease in incontinence episodes as well as reduced episodes of micturitions and urgency compared to placebo. ${ }^{80}$ Compared to antimuscarinic agents, mirabegron as monotherapy has a similar efficacy with less side effects, which may explain the improved adherence and treatment longevity with mirabegron. Mirabegron may also be useful in men with both voiding and storage symptoms due to bladder outlet obstruction. In the RCT, Nitti et al found that mirabegron did not adversely affect voiding urodynamics compared with placebo after 8 weeks of treatment. ${ }^{81}$

The side effects of mirabegron are generally mild and well tolerated. The most frequent adverse events associated with mirabegron are nausea, diarrhea, constipation, dizziness, and headache. A less common adverse event of mirabegron is elevation in blood pressure and hence mirabegron should not be used in patients with uncontrolled hypertension. The effects of mirabegron on cognitive functions, pharmacokinetic interactions with other drugs, and long-term adverse events need to be further evaluated. ${ }^{82}$ 


\section{OAB Treatment in Elderly Patients}

Since anticholinergics have similar efficacy, patient comorbidity is the main factor influencing the choice of medication. Elderly patients receiving anticholinergic drugs are at higher risk of confusion, falls and fractures, and therefore anticholinergics should be avoided in patients with dementia, cognitive dysfunction or delirium. ${ }^{82}$

Oxybutynin may worsen cognitive function in elderly patients, but solifenacin, darifenacin, fesoterodine and trospium have not been shown to cause cognitive dysfunction in elderly people in short-term studies. ${ }^{2}$ As such, EAU guidelines advise that long-term antimuscarinic treatment should be used with caution in elderly patients, especially those who are at risk of, or have, cognitive dysfunction. ${ }^{2}$

Mirabegron may be considered in the elderly as an alternative to antimuscarinics. A meta-analysis by Wagg et al demonstrated that Mirabegron at a dose of $25 \mathrm{mg}$ and $50 \mathrm{mg}$ was effective and well tolerated in $\mathrm{OAB}$ patients aged $\geq 65$ and $\geq 75$ years. ${ }^{83}$

\section{Combination of Antimuscarinic and Beta-3 Agonist}

The BESIDE study investigated improvements in $\mathrm{OAB}$ symptoms and refractory UI comparing mirabegron $50 \mathrm{mg}$ plus solifenacin $5 \mathrm{mg}$ versus solifenacin 5 or $10 \mathrm{mg}$ alone. They demonstrated that significantly more patients treated with the combination of mirabegron and solifenacin achieved clinically meaningful improvements in incontinence and micturition frequency compared to solifenacin monotherapy alone, at either dose. ${ }^{84}$

\section{Duloxetine}

Duloxetine is a potent serotonin (5-hydroxytryptamine, 5-HT) and noradrenaline re-uptake inhibitor with little or no affinity for cholinergic receptors. Duloxetine increases the levels of serotonin and norepinephrine in the pudendal motor nucleus and thereby increases bladder capacity and striated urethral sphincter activity. ${ }^{85}$ Duloxetine increases urethral pressure and maximum urethral closure pressure and sphincter width after 8 weeks of treatment. ${ }^{86}$

Duloxetine was initially developed for use in patients with major depressive disorder and chronic pain. In 2004, duloxetine became the first medication approved for the treatment of women with moderate-to-severe stress urinary incontinence. Duloxetine is administered at $40 \mathrm{mg}$ twice daily for up to 8 weeks, with minimal safety concerns for this duration.
However, no evidence is available on maintenance regimens. Cure rates of $10 \%$ may be achieved with doses of $80 \mathrm{mg} / \mathrm{d} .^{2}$

EAU guidelines advise that duloxetine should be offered in selected patients with symptoms of SUI when surgery is not indicated. They also advise that duloxetine should be initiated and withdrawn using dose titration because of the high risk of adverse events, including GI upset and reports of suicidal ideation. ${ }^{50}$

\section{Desmopressin}

Desmopressin is a synthetic analog of vasopressin, aka antidiuretic hormone. It is widely used in the treatment of diabetes insipidus and nocturnal enuresis. Vasopressin is produced by the posterior pituitary gland and secreted in states of hypovolemia and hyperosmolality, which facilitates the urine concentrating mechanism through interaction with vasopressin type 2 receptor. ${ }^{87}$

There has been growing interest in the use of desmopressin for the treatment of nocturia for whom nocturnal polyuria is prevalent. Desmopressin is available in formulations for oral, parenteral and nasal administration. Men usually benefit from a minimum of $50 \mu \mathrm{g}$, whereas a dosage of $25 \mu \mathrm{g}$ orally disintegrating sublingual desmopressin appears to be ideal for women. Increasing doses of desmopressin reduces the number of nocturnal voids and voided volumes, as well as increasing the duration of the first sleep period. ${ }^{88}$ In one study, desmopressin resulted in more than an hour of additional sleep before the first void and 0.72 fewer voids per night than those on placebo. ${ }^{89}$

Typical adverse effects of desmopressin include headache, hyponatremia, insomnia, dry mouth, hypertension, abdominal pain, peripheral edema and nausea. Among these, hyponatremia is the only potential life-threatening complication and therefore vasopressin is contraindicated in patients with baseline level of sodium less than 130 $\mathrm{mmol} / \mathrm{L}$. Since hyponatremia is usually encountered in individuals $>65$ years old, particular attention should be paid when considering vasopressin in these patient populations.

\section{Conclusion}

UI is a bothersome and distressing symptom, which can have a significant impact on patients, families and carers. Conservative and non-invasive measures are often effective in improving symptoms and should be tried in all cases in the first instance. Ideally, the combined use of these therapies should be utilized as part of a comprehensive and individualized treatment program for UI. 


\section{Disclosure}

The authors report no conflicts of interest in this work.

\section{References}

1. Irwin DE, Milson I, Hunskaar S, et al. Population-based survey of urinary incontinence, overactive bladder, and other lower urinary tract symptoms in five countries: results of the EPIC study. Eur Urol. 2006;50(6):1306-1314. doi:10.1016/j.eururo.2006.09.019

2. Nambiar AK, Bosch R, Cruz F, et al. EAU guidelines on assessment and nonsurgical management of urinary incontinence. Eur Urol. 2018;73(4):596-609. doi:10.1016/j.eururo.2017.12.031

3. Abrams P, Cardozo L, Wagg A, Wein A, editors. 6th international consultation on incontinence. Tokyo; 2016.

4. Kobashi KC, Albo ME, Dmochowski RR, et al. Surgical treatment of female urinary incontinence: AUA/SUFU guideline. $J$ Urol. 2017;198:875. doi:10.1016/j.juro.2017.06.061

5. Lightner DJ, Gomelsky A, Souter L, et al. Diagnosis and treatment of overactive bladder (non-neurogenic) in adults: AUA/SUFU guideline. J Urol. 2019;202:558. doi:10.1097/JU.0000000000000309

6. Gormley EA, Lightner DJ, Burgio KL, et al. Diagnosis and treatment of overactive bladder (non-neurogenic) in adults: AUA/SUFU guideline. J Urol. 2012;188:2455. doi:10.1016/j.juro.2012.09.079

7. NICE guidelines: urinary incontinence and pelvic organ prolapse in women (NG123); April 2019.

8. Fenner DE, Trowbridge ER, Patel DA, et al. Establishing the prevalence of incontinence study: racial differences in women's patterns of urinary incontinence. $J$ Urol. 2018;179(4):1455-1460. doi:10.1016/j.juro.2007.11.051

9. Bradley CS, Erickson BA, Messersmith EE, et al. Evidence of the impact of diet, fluid intake, caffeine, alcohol and tobacco on lower urinary tract symptoms: a systematic review. J Urol. 2017;198 (5):1010-1020. doi:10.1016/j.juro.2017.04.097

10. Subak LL, Richter HE, Hunskaar S. Obesity and urinary incontinence: epidemiology and clinical research update. J Urol. 2009;182(6 Suppl):S2-S7. doi:10.1016/j.juro.2009.08.071

11. Kawahara T, Ito H, Yao M, Uemura H. Impact of smoking habit on overactive bladder symptoms and incontinence in women. Int $J$ Urol. 2020;27(12):1078-1086. doi:10.1111/iju.14357

12. Drake MJ, Nixon PM, Crew JP. Drug-induced bladder and urinary disorders. Incidence, prevention and management. Drug Saf. 1998;19 (1):45-55. doi:10.2165/00002018-199819010-00004

13. Abrams P, Avery K, Gardener N, Donovan J; ICIQ Advisory Board. The international consultation on incontinence modular questionnaire. J Urol. 2006;175(3 Pt 1):1063-1066. doi:10.1016/ S0022-5347(05)00348-4

14. Ouslander JG, Schapira M, Schnelle JF, et al. Does eradicating bacteriuria affect the severity of chronic urinary incontinence in nursing home residents? Ann Intern Med. 1995;122:749-754. doi:10.7326/0003-4819-122-10-199505150-00003

15. Drake MJ, Doumouchtsis SK, Hashim H, Gammie A. Fundamentals of urodynamic practice, based on international continence society good urodynamic practices recommendations. Neurourol Urodyn. 2018;37(S6):S50-S60. doi:10.1002/nau.23773

16. Alling Moller L, Lose G, Jorgensen T. Risk factors for lower urinary tract symptoms in women 40 to 60 years of age. Obstet Gynecol. 2000;96(3):446-451. doi:10.1016/S0029-7844(00)00915-7

17. Byles J, Millar CJ, Sibbritt DW, et al. Living with urinary incontinence: a longitudinal study of older women. Age Ageing. 2009;38 (3):333-338. doi:10.1093/ageing/afp013

18. Kaplan SA, Dmochowski R, Cash BD, et al. Systematic review of the relationship between bladder and bowel function: implications for patient management. Int $J$ Clin Pract. 2013;67(3):205-216. doi:10.1111/ijcp. 12028
19. Schnelle JF, Leung FW, Rao SSC, et al. A controlled trial of an intervention to improve urinary and fecal incontinence and constipation. $J$ Am Geriatr Soc. 2010;58(8):1504-1511. doi:10.1111/j.1532-5415.2010.02978.x

20. Brazzelli M, Shirran E, Vale L, et al. Absorbent products for containing urinary and/or fecal incontinence in adults. $J$ Wound Ostomy Continence Nurs. 2002;29(1):45-54.

21. Chartier-Kastler E, Ballanger P, Petit J, et al. Randomized, crossover study evaluating patient preference and the impact on quality of life of urisheaths vs absorbent products in incontinent men. BJU Int. 2011;108(2):241-247. doi:10.1111/j.1464-410X.2010.09736.x

22. McMurdo ME, Davey PG, Elder MA, et al. A cost-effectiveness study of the management of intractable urinary incontinence by urinary catheterisation or incontinence pads. $J$ Epidemiol Community Health. 1992;46(3):222-226. doi:10.1136/jech.46.3.222

23. Saint S, Kaufman SR, Rogers MAM, et al. Condom versus indwelling urinary catheters: a randomized trial. J Am Geriatr Soc. 2006;54 (7):1055-1061. doi:10.1111/j.1532-5415.2006.00785.x

24. Jahn P, Beutner K, Langer G, et al. Types of indwelling urinary catheters for long-term bladder drainage in adults. Cochrane Database Syst Rev. 2012;10:CD004997.

25. Hunter KF, Bharmal A, Moore KN, et al. Long-term bladder drainage: suprapubic catheter versus other methods: a scoping review. Neurourol Urodyn. 2013;32(7):944-951. doi:10.1002/nau.22356

26. Niel-Weise BS, van den Broek PJ, da Silva EM, et al. Urinary catheter policies for long-term bladder drainage. Cochrane Database Syst Rev. 2012;8:CD004201.

27. Fisher H, Oluboyede Y, Chadwick T, et al. Continuous low-dose antibiotic prophylaxis for adults with repeated urinary tract infections (AnTIC): a randomised, open-label trial. Lancet Infect Dis. 2018;18 (9):957-968. doi:10.1016/S1473-3099(18)30279-2

28. Moore KN, Schieman S, Ackerman T, et al. Assessing comfort, safety, and patient satisfaction with three commonly used penile compression devices. Urology. 2004;63(1):150-154. doi:10.1016/j. urology.2003.08.034

29. Lipp A, Shaw C, Glavind K, et al. Mechanical devices for urinary incontinence in women. Cochrane Database Syst Rev. 2014;12: CD001756.

30. Le Berre M, Presse N, Morin M, et al. What do we really know about the role of caffeine on urinary tract symptoms? A scoping review on caffeine consumption and lower urinary tract symptoms in adults. Neurourol Urodyn. 2020;39(5):1217-1233. doi:10.1002/nau.24344

31. Swithinbank L, Hashim H, Abrams P, et al. The effect of fluid intake on urinary symptoms in women. $J$ Urol. 2005;174(1):187-189. doi:10.1097/01.ju.0000162020.10447.31

32. Dowd TT, Campbell JM, Jones JA, et al. Fluid intake and urinary incontinence in older community-dwelling women. $J$ Community Health Nurs. 1996;13(3):179-186. doi:10.1207/ s15327655jchn1303_5

33. Hashim H, Abrams P. How should patients with an overactive bladder manipulate their fluid intake? BJU Int. 2008;102(1):62-66. doi:10.1111/j.1464-410X.2008.07463.x

34. Hunskaar S. A systematic review of overweight and obesity as risk factors and targets for clinical intervention for urinary incontinence in women. Neurourol Urodyn. 2008;27(8):749-757. doi:10.1002/ nau. 20635

35. Subak LL, Wing R, West DS, et al. Weight loss to treat urinary incontinence in overweight and obese women. $N$ Engl $J$ Med. 2009;360(5):481-490. doi:10.1056/NEJMoa0806375

36. Knepfler T, Valero E, Triki E, et al. Bariatric surgery improves female pelvic floor disorders. J Visc Surg. 2016;153(2):95-99. doi:10.1016/j. jviscsurg.2015.11.011

37. Subak LL, King WC, Belle SH, et al. Urinary incontinence before and after bariatric surgery. JAMA Intern Med. 2015;175 (8):1378-1387. doi:10.1001/jamainternmed.2015.2609 
38. Eliasson K, Nordlander I, Larson B, et al. Influence of physical activity on urinary leakage in primiparous women. Scand J Med Sci Sports. 2005;15(2):87-94. doi:10.1111/j.1600-0838.2004.407.x

39. Kikuchi A, Niu K, Ikeda Y, et al. Association between physical activity and urinary incontinence in a community-based elderly population aged 70 years and over. Eur Urol. 2007;52(3):868-874. doi:10.1016/j.eururo.2007.03.041

40. Hannestad YS, Rortveit G, Daltveit AK, et al. Are smoking and other lifestyle factors associated with female urinary incontinence? The Norwegian EPINCONT study. BJOG. 2003;110(3):247-254. doi:10.1046/j.1471-0528.2003.02327.x

41. Nygaard I, DeLancey JO, Arnsdorf LI, et al. Exercise and incontinence. Obstet Gynecol. 1990;75(5):848-851.

42. Brown WJ, Miller YD. Too wet to exercise? Leaking urine as a barrier to physical activity in women. J Sci Med Sport. 2001;4 (4):373-378. doi:10.1016/S1440-2440(01)80046-3

43. Kim H, Suzuki T, Yoshida Y, et al. Effectiveness of multidimensional exercises for the treatment of stress urinary incontinence in elderly community-dwelling Japanese women: a randomized, controlled, crossover trial. J Am Geriatr Soc. 2007;55(12):1932-1939. doi:10.1111/j.1532-5415.2007.01447.x

44. Kim H, Yoshida H, Suzuki T, et al. The effects of multidimensional exercise treatment on community-dwelling elderly Japanese women with stress, urge, and mixed urinary incontinence: a randomized controlled trial. Int $J$ Nurs Stud. 2011;48(10):1165-1172. doi:10.1016/j.ijnurstu.2011.02.016

45. Bump RC, McClish DK. Cigarette smoking and urinary incontinence in women. Am J Obstet Gynecol. 1992;167(5):1213-1218. doi:10.1016/S0002-9378(11)91691-3

46. Imamura M, Abrams P, Bain C, et al. Systematic review and economic modelling of the effectiveness and cost-effectiveness of non-surgical treatments for women with stress urinary incontinence. Health Technol Assess. 2010;14(40):1-188. doi:10.3310/hta14400

47. Available from: https://www.ics.org/glossary/conservativemanagment female/behaviouralandcognitivetherapies. Accessed August 3, 2021.

48. Bo K, Frawley HC, Haylen BT, et al. An international urogynecological association (IUGA) /international continence society (ICS) joint report on the terminology for the conservative management of pelvic floor dysfunction (in committee review). Int Urogynecol J. 2017;28:191. doi:10.1007/s00192-016-3123-4

49. Wallace SA, Roe B, Williams K, Palmer M. Bladder training for urinary incontinence in adults. Cochrane Database Syst Rev. 2004;1. doi:10.1002/14651858.CD001308.pub2

50. Burkhard FC, Bosch JLHR, Cruz F, Lemack GE, Nambiar AK, Thiruchelvam N. EAU guidelines on urinary incontinence in adults; 2018.

51. Newman D, Butcher HK. Evidence-based practice guideline. prompted voiding for individuals with urinary incontinence. $J$ Gerontol Nurs. 2019;45(2):14-26. doi:10.3928/0098913420190111-03

52. Dumoulin C, Cacciari LP, Hay-Smith EJC. Pelvic floor muscle training versus no treatment, or inactive control treatments, for urinary incontinence in women. Cochrane Database Syst Rev. 2018;10. doi:10.1002/14651858.CD005654.pub4

53. Sherburn M, Bird M, Carey M, et al. Incontinence improves in older women after intensive pelvic floor muscle training: an assessor-blinded randomized controlled trial. Neurourol Urodyn. 2011;30(3):317. doi:10.1002/nau.20968

54. Berghmans B, van Waalwijk van Doorn E, Nieman F, et al. Efficacy of physical therapeutic modalities in women with proven bladder overactivity. Eur Urol. 2002;41:581. doi:10.1016/S0302-2838(02) 00178-1

55. Anderson CA, Omar MI, Campbell SE, Hunter KF, Cody JD, Glazener CMA. Conservative management for postprostatectomy urinary incontinence. Cochrane Database Syst Rev. 2015;1. doi:10.1002/14651858.CD001843.pub5
56. Wang, Wang W, Huang QM, et al. Effectiveness of preoperative pelvic floor muscle training for urinary incontinence after radical prostatectomy: a meta-analysis. BMC Urol. 2014;14(1):99.

57. Stewart F, Gameiro LF, El Dib R, Gameiro MO, Kapoor A, Amaro JL. Electrical stimulation with non-implanted electrodes for overactive bladder in adults. Cochrane Database Syst Rev. 2016;12. doi:10.1002/14651858.CD010098.pub4

58. Alka AB, Tailor V, Fernando R, et al. Posterior tibial nerve stimulation for overactive bladder-techniques and efficacy. Int Urogynecol J. 2020;31:865-870. doi:10.1007/s00192-019-04186-3

59. de Wall L, Heesakkers J. Effectiveness of percutaneous tibial nerve stimulation in the treatment of overactive bladder syndrome. Re Rep Urol. 2017;9:145-157. doi:10.2147/RRU.S124981

60. Sun-Ho P, Han S-R, Kwon O-J, et al. Acupuncture for the treatment of urinary incontinence: a review of randomized controlled trials. Exp Ther Med. 2013;6(3):773-780. doi:10.3892/etm.2013.1210

61. Wang Y, Zhishun L, Peng W, Zhao J, Liu B. Acupuncture for stress urinary incontinence in adults. Cochrane Database Syst Rev. 2013;7. doi:10.1002/14651858.CD009408.pub2

62. Liu Z, Liu Y, Xu H, et al. Effect of electroacupuncture on urinary leakage among women with stress urinary incontinence: a randomized clinical trial. JAMA. 2017;317:2493-2501. doi:10.1001/jama.2017.7220

63. Zhao Y, Zhou J, Mo Q, et al. Acupuncture for adults with overactive bladder: a systematic review and meta-analysis of randomized controlled trials. Medicine (Baltimore). 2018;97(8):e9838. doi:10.1097/ MD.0000000000009838

64. Iosif CS, Batra S, Ek A, Astedt B. Estrogen receptors in the human female lower urinary tract. Am J Obstet Gynecol. 1981;141 (7):817-820. doi:10.1016/0002-9378(81)90710-9

65. Rud T, Andersson KE, Asmussen M, Hunting A, Ulmsten U. Factors maintaining the intraurethral pressure in women. Invest Urol. 1980;17(4):343-347.

66. Cody JD, Jacobs ML, Richardson K, Moehrer B, Hextall A. Oestrogen therapy for urinary incontinence in post-menopausal women. Cochrane Database Syst Rev. 2012;10(10):CD001405.

67. Andersson KE, Chapple C, Wein A. The basis for drug treatment of the overactive bladder. World J Urol. 2001;19(5):294-298. doi:10.1007/PL00007101

68. Andersson KE. Antimuscarinics for treatment of overactive bladder. Lancet Neurol. 2004;3(1):46-53. doi:10.1016/S1474-4422(03)006227

69. Harvey MA, Baker K, Wells GA. Tolterodine versus oxybutynin in the treatment of urge urinary incontinence: a meta-analysis. $\mathrm{Am}$ J Obstet Gynecol. 2001;185(1):56-61. doi:10.1067/mob.2001.116371

70. Nabi G, Cody JD, Ellis G, Herbison P, Hay-Smith J. Anticholinergic drugs versus placebo for overactive bladder syndrome in adults. Cochrane Database Syst Rev. 2006;18(4):CD003781.

71. Ouslander JG. Management of overactive bladder. $N$ Engl J Med. 2004;350(8):786-799. doi:10.1056/NEJMra032662

72. Ellsworth P, Kirshenbaum E. Update on the pharmacologic management of overactive bladder: the present and the future. Urol Nurs. 2010;30(1):29-38, 53. doi:10.7257/1053-816X.2010.30.1.29

73. Gray SL, Anderson ML, Dublin S, et al. Cumulative use of strong anticholinergics and incident dementia: a prospective cohort study. JAMA Intern Med. 2015;175(3):401-407. doi:10.1001/ jamainternmed.2014.7663

74. D’Souza AO, Smith MJ, Miller LA, Doyle J, Ariely R. Persistence, adherence, and switch rates among extended-release and immediate-release overactive bladder medications in a regional managed care plan. J Manag Care Pharm. 2008;14(3):291-301. doi:10.18553/jmcp.2008.14.3.291

75. Benner JS, Nichol MB, Rovner ES, et al. Patient-reported reasons for discontinuing overactive bladder medication. BJU Int. 2010;105 (9):1276-1282. doi:10.1111/j.1464-410X.2009.09036.x 
76. Yu YF, Nichol MB, Yu AP, Ahn J. Persistence and adherence of medications for chronic overactive bladder/urinary incontinence in the California Medicaid program. Value Health. 2005;8(4):495-505. doi:10.1111/j.1524-4733.2005.00041.x

77. Igawa Y, Yamazaki Y, Takeda H, et al. Possible beta 3-adrenoceptormediated relaxation of the human detrusor. Acta Physiol Scand. 1998;164(1):117-118. doi:10.1046/j.1365-201X.1998.00406.x

78. Tyagi $\mathrm{P}$, Tyag V. Mirabegron, a $\beta_{3}$-adrenoceptor agonist for the potential treatment of urinary frequency, urinary incontinence or urgency associated with overactive bladder. IDrugs. 2010;13 (10):713-722.

79. Sacco E, Bientinesi R. Mirabegron: a review of recent data and its prospects in the management of overactive bladder. Ther Adv Urol. 2012;4(6):315-324. doi:10.1177/1756287212457114

80. Cui Y, Zong H, Yang C, Yan H, Zhang Y. The efficacy and safety of mirabegron in treating OAB: a systematic review and meta-analysis of Phase III trials. Int Urol Nephrol. 2014;46(1):275-284. doi:10.1007/s11255-013-0509-9

81. Nitti VW, Rosenbery S, Mitcheson DH, et al. Urodynamics and safety of the $\beta 3$-adrenoceptor agonist mirabegron in males with lower urinary tract symptoms and bladder outlet obstruction. J Urol. 2013;190(4):1320-1327. doi:10.1016/j.juro.2013.05.062

82. Caremel R, Loutochin O, Corcos J. What do we know and not know about mirabegron, a novel $\beta 3$ agonist, in the treatment of overactive bladder? Int Urogynecol J. 2014;25(2):165-170. doi:10.1007/s00192013-2161-4

83. Wagg A, Cardozo L, Nitti VW, et al. The efficacy and tolerability of the beta3-adrenoceptor agonist mirabegron for the treatment of symptoms of overactive bladder in older patients. Age Ageing. 2014;43 (5):666-675. doi:10.1093/ageing/afu017
84. MacDiarmid S, Al-Shukri S, Barkin J, et al. Mirabegron as add-on treatment to solifenacin in patients with incontinent overactive bladder and an inadequate response to solifenacin monotherapy. $J$ Urol. 2016;196:809-818. doi:10.1016/j.juro.2016.03.174

85. Thor KB, Katofiasc MA. Effects of duloxetine, a combined serotonin and norepinephrine reuptake inhibitor, on central neural control of lower urinary tract function in the chloralose-anesthetized female cat. J Pharmacol Exp Ther. 1995;274(2):1014-1024.

86. Athanasiou S, Chaliha C, Digesu GA, et al. The effects of duloxetine on urethral function and sphincter morphology. Int Urogynecol J Pelvic Floor Dysfunct. 2007;18(7):763-767. doi:10.1007/s00192006-0230-7

87. Chung E. Desmopressin and nocturnal voiding dysfunction: clinical evidence and safety profile in the treatment of nocturia. Expert Opin Pharmacother. 2018;19(3):291-298. doi:10.1080/ 14656566.2018.1429406

88. Weiss JP, Zinner NR, Klein BM, Nørgaard JP. Desmopressin orally disintegrating tablet effectively reduces nocturia: results of a randomized, double-blind, placebo-controlled trial. Neurourol Urodyn. 2012;31(4):441-447. doi:10.1002/nau.22243

89. Mattiasson A, Abrams P, Van Kerrebroeck P, Walter S, Weiss J. Efficacy of desmopressin in the treatment of nocturia: a double-blind placebo-controlled study in men. BJU Int. 2002;89 (9):855-862. doi:10.1046/j.1464-410X.2002.02791.x
International Journal of General Medicine

\section{Publish your work in this journal}

The International Journal of General Medicine is an international, peer-reviewed open-access journal that focuses on general and internal medicine, pathogenesis, epidemiology, diagnosis, monitoring and treatment protocols. The journal is characterized by the rapid reporting of reviews, original research and clinical studies

\section{Dovepress}

across all disease areas. The manuscript management system is completely online and includes a very quick and fair peer-review system, which is all easy to use. Visit http://www.dovepress.com/ testimonials.php to read real quotes from published authors. 